\title{
What parathyroid hormone levels should we aim for in children with stage 5 chronic kidney disease; what is the evidence?
}

\author{
Lesley Rees
}

Received: 10 September 2007 /Revised: 16 October 2007 / Accepted: 17 October 2007 / Published online: 28 November 2007

(C) IPNA 2007

\begin{abstract}
The bone disease that occurs as a result of chronic kidney disease (CKD) is not only debilitating but also linked to poor growth and cardiovascular disease. It is suspected that abnormal bone turnover is the main culprit for these poor outcomes. Plasma parathyroid hormone (PTH) levels are used as a surrogate marker of bone turnover, and there is a small number of studies in children that have attempted to identify the range of PTH levels that correlates with normal bone histology. It is clear that high PTH levels are associated with high bone turnover, although the range is wide. However, the ability of PTH levels to distinguish between low and normal bone turnover is less clear. This is an important issue, because current guidelines for calcium and phosphate management are based upon there being an "optimum" range for PTH. This editorial takes a critical look at the evidence upon which these recommendations are based.
\end{abstract}

Keywords Parathyroid hormone (PTH) · Bone turnover Growth · Vascular calcification

\section{Introduction}

Abnormal mineral metabolism and altered bone structure and composition occur early in the course of chronic kidney disease (CKD). If untreated, bony deformities can result, affecting both mobility and growth. Although such severe effects are now rarely seen, bone-related problems that adversely affect quality of life, including bone and joint pain

\section{Rees $(\triangle)$}

Great Ormond Street Hospital for Children NHS Trust,

Great Ormond Street,

London WC1N 3JH, UK

e-mail: ReesL@gosh.nhs.uk and fractures, are the most common complaints in young adult survivors of paediatric renal failure programmes [1]. Furthermore, it is not only morbidity but also mortality that is affected by abnormal mineral metabolism: the association with extra skeletal and, in particular, vascular calcification, is strongly suggestive of a causative link, although the pathological mechanisms are yet to be unravelled. In order to reflect the complex issues surrounding these areas, it has been suggested that CKD-mineral and bone disorder (CKD-MBD) should be used as an encompassing definition and "renal osteodystrophy" be reserved for description of bone morphology [2].

The importance of the optimum range for parathyroid hormone

Current management of CKD-MBD hinges on the concept of an optimum range for plasma parathyroid hormone (PTH) levels, which is a range that maintains normal bone turnover without increasing the risk for ectopic calcification. This range may change with time, as abnormalities in PTH secretion and bone turnover begin to occur early in the course of CKD and can lead to increasing skeletal resistance to PTH as CKD progresses. Therefore, increasingly higher PTH levels are necessary to maintain normal bone turnover, and a higher plasma calcium level is needed to suppress PTH secretion, unless normal mineral metabolism is maintained. Hyperparathyroidism evolves, because phosphate retention, decreased dietary intake of calcium and vitamin $\mathrm{D}$, and decreased synthesis of 1,25-dihydroxyvitamin D3 [1,25(OH)2D3] in the kidney act to increase PTH secretion via the calcium sensing receptors (CaSRs) and the vitamin D receptors (VDRs) in the parathyroid gland. Persistent parathyroid stimulation results in parathyroid hyperplasia, reduced VDR and CaSR expression, less suppression of PTH by calcium and 1,25(OH) 
2D3, and nodular hyperplasia, which may culminate in the need for parathyroidectomy. What is not known is whether this process can be prevented if mineral metabolism and PTH levels are maintained within the normal range throughout the course of CKD, so that the parathyroid gland is never allowed to escape normal control mechanisms [3].

Bone tissue is formed by osteoblasts, maintained by osteocytes and resorbed by osteoclasts. Activity is increased by PTH. The spectrum of bone abnormality ranges from low bone turnover [adynamic bone disease (ABD)], when there is normal or reduced osteoid and low or diminished numbers of osteoclasts and osteoblasts, to high bone turnover, when there are increased osteoclasts and bone resorption, increased osteoblasts and bone formation, and increased osteoid and non-lamellar bone. A mixed picture can also occur. The optimum range for PTH is one that maintains normal bone turnover. PTH levels can be manipulated into this range by the control of plasma calcium and phosphate by diet, phosphate binders, dialysis and prescription of vitamin D. Maintaining normal bone turnover is important for two reasons: firstly, to prevent bone deformity, pain and fractures and to optimise growth; and secondly, to prevent soft tissue calcification. The risks of extra skeletal calcification are thought to be increased with both low and high bone turnover, because both types result in high plasma calcium and phosphate levels: low bone turnover because of the inability of bone to buffer changes in plasma calcium and phosphate, and high turnover because high PTH levels mobilise calcium and phosphate from bone, increase tubular reabsorption of calcium, and promote gut absorption of calcium and phosphate by hydroxylation of 25 , OHD3. Furthermore, PTH itself is thought to be an independent risk factor for myocardial fibrosis, arteriolar thickening, and hypertension [4].

\section{Current guidelines for PTH management}

There are detailed guidelines from the USA [Kidney Disease Outcomes Quality Initiative (KDOQI)] [5] and Europe [6] on PTH management, and all aspects of calcium, phosphate and vitamin D control, in order to achieve these aims. European recommendations for CKD are that the plasma PTH should be kept in the normal range until stage 5, when 2- to 3-times the upper limit of normal is recommended. KDOQI sets higher levels of up to twice the upper limit of normal in CKD stage 4 and 3- to 5-times on dialysis. Clearly, if we are to minimise the morbidity and mortality from CKDMBD it is vital that we "get it right". But what if we have "got it wrong"? Many of our data have been extrapolated from studies of adults, but active bone growth in children and their requirements for more calcium and phosphate may present a different homoeostatic mechanism. Furthermore, is there sufficient evidence to allow us to prescribe one set of guidelines for all? For example, should the child presenting antenatally whose condition is managed with normal range PTH levels suddenly change treatment to allow PTH levels of 2 - to 3-times normal at stage $5 \mathrm{CKD}$ as per current guidelines? Surely such a child is different from one who first presents in stage $5 \mathrm{CKD}$ who has had many years of uncontrolled hyperparathyroidism? What about the effect of variable plasma phosphate control, which will independently affect PTH levels? Finally, there has to be a word of caution about the value of PTH as a marker of bone turnover; its short halflife means that fluctuations are very likely, and the presence of PTH fragments, which are detected by the majority of current assays, may increase with the severity of both CKD and hyperparathyroidism [7].

\section{What is the evidence for the optimum range for plasma PTH levels?}

PTH levels, bone turnover and bone biopsies

Clearly, the only way we can know the rate of bone turnover is by bone biopsy, but this is an invasive and expensive procedure, currently undertaken in very few paediatric centres. PTH is, therefore, currently used as the best available surrogate marker of bone turnover. Recommendations for optimum PTH levels are based on the pioneering work of Salusky, who has been the leader in the field of paediatric bone biopsy and who has been able to correlate plasma PTH levels with bone turnover $[8,9,10]$ (Table 1, Fig. 1).

The first description of bone histology in children with CKD was from Australia in 1982. Bone abnormalities included high turnover, osteomalacia and mixed lesions and were present in all 23 children with a glomerular filtration rate $(\mathrm{GFR})<20 \mathrm{ml} / \mathrm{min}$ per $1.73 \mathrm{~m}^{2}$ body surface area. PTH levels were high, but the assay available at that time picked up carboxy terminal fragments as well as the intact hormone [11]. A paper from Toronto in 1988 showed that treatment with 1 alpha-hydroxycholecalciferol resulted in significant improvement in PTH levels and bone histology in 12 peritoneal dialysis (PD) patients [12]. There are five paediatric studies since 1990, and unpublished data from our centre, that have used newer "intact" PTH assays to look at their correlation with bone histology (Table 1). The first three studies $[8,9,10]$ are all from Salusky's group, and are of patients dialysed in their unit between 1983 and 1992. There are two more recent studies from Poland [13] and Turkey [14]. The patients from our unit had bone biopsies taken prior to starting dialysis, at the time of insertion of access or at transplantation.

High-turnover bone was characterised by PTH levels above normal in all studies, although the variation was wide, ranging from just above the upper limit of normal $(76 \pm 14 \mathrm{pg} / \mathrm{ml})$, 


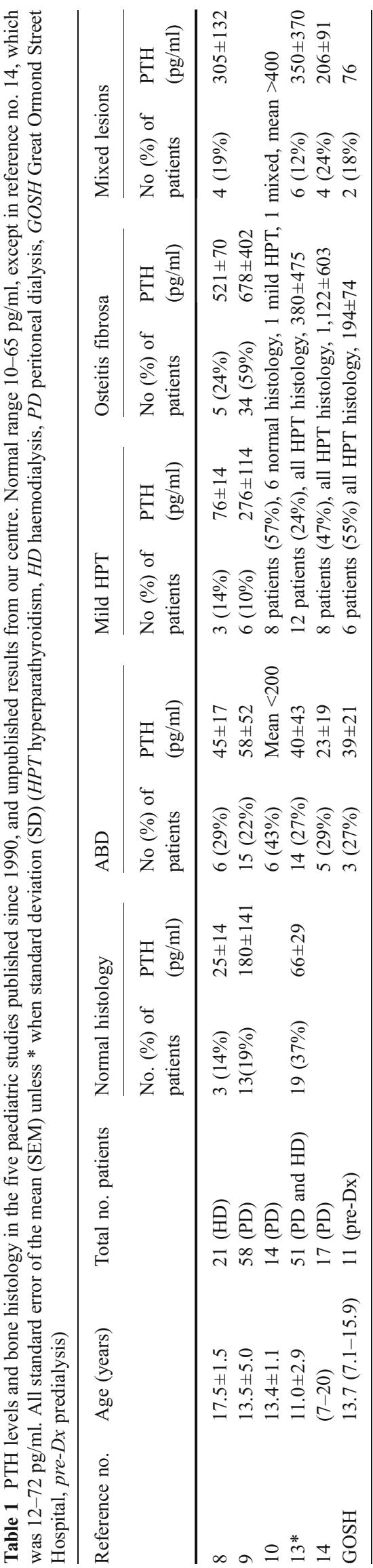

when changes were mild [8], to 16 -times normal $(1,122 \pm$ $603 \mathrm{pg} / \mathrm{ml}$ ) with osteitis fibrosa [15].

Patients with ABD clearly had lower PTH levels than those with osteitis fibrosa (although not lower than those with mild hyperparathyroidism) [8]. However, the ability of PTH levels to distinguish between ABD and normal histology is less clear. Figure 1 shows the PTH levels in the three studies that have identified patients with normal bone and ABD. Even within the same centre, there was no consistency, with PTH levels being lower with normal bone than with ABD in patients on haemodialysis (HD) [8], but the reverse in PD patients [9]. Levels were particularly high in the second study, with a wide scatter, but analysis of results in these patients suggested that $\mathrm{PTH}<150 \mathrm{pg} / \mathrm{ml}$ and calcium $>10 \mathrm{mg} / \mathrm{dl}(>2.50 \mathrm{mmol} / \mathrm{l})$ was indicative of low turnover, and PTH $>200 \mathrm{pg} / \mathrm{ml}$ with calcium $<10 \mathrm{mg} / \mathrm{dl}$ (2.50 $\mathrm{mmol} / \mathrm{l})$ indicated high turnover [9]. In the Polish group a PTH level of $<50 \mathrm{pg} / \mathrm{ml}$ was suggestive of ABD, but the difference from normal bone was not significant [13]. Other evidence for PTH levels associated with ABD comes from a study of the role of intermittent oral administration compared with intraperitoneal administration of calcitriol (dose $1.26(0.61-2.88) \mu \mathrm{g} \times 3$ per week for a year) in 14 patients with high-turnover disease. There were no patients with normal histology results. Six patients developed ABD, with a mean PTH of approximately $200 \mathrm{pg} / \mathrm{ml}$, whereas the mean for high-turnover disease was around $400 \mathrm{pg} / \mathrm{ml}$. However, again, the standard errors were wide [10].

What are the potential problems with these studies? Patient numbers are small in some; there are very few young children, and, indeed, some patients might have ceased growing; some children in the earlier studies had received aluminium, and two had undergone parathyroidectomies (both recognised causes of $\mathrm{ABD}$ ); some had transplants that had failed; phosphate control and vitamin $\mathrm{D}$ doses were variable, and the majority received dialysate calcium of $1.75 \mathrm{mmol} / \mathrm{l}$, which is higher than is most commonly used now.

PTH levels and growth

Intuitively, it might be expected that poor growth would occur with $\mathrm{ABD}$, and, conversely, that, if a child is growing well, ABD is unlikely. The only published paper to look at bone histology and growth is by Salusky's group in 1998 [15]. Their purpose was also to study the effect of different ways of administering vitamin D. Sixteen patients were treated for a year with intermittent doses of calcitriol in comparison to daily treatment during the preceding year. The rate of growth was unchanged in the patients taking calcitriol daily, but, in the patients taking intermittent doses of calcitriol, PTH correlated with the change in height standard deviation score (HtSDS). Growth was particularly 
Fig. 1 PTH levels and bone histology in studies of children on dialysis in whom normal bone and adynamic bone disease have been identified. * Represent SEM except in ref 13 where they represent SD

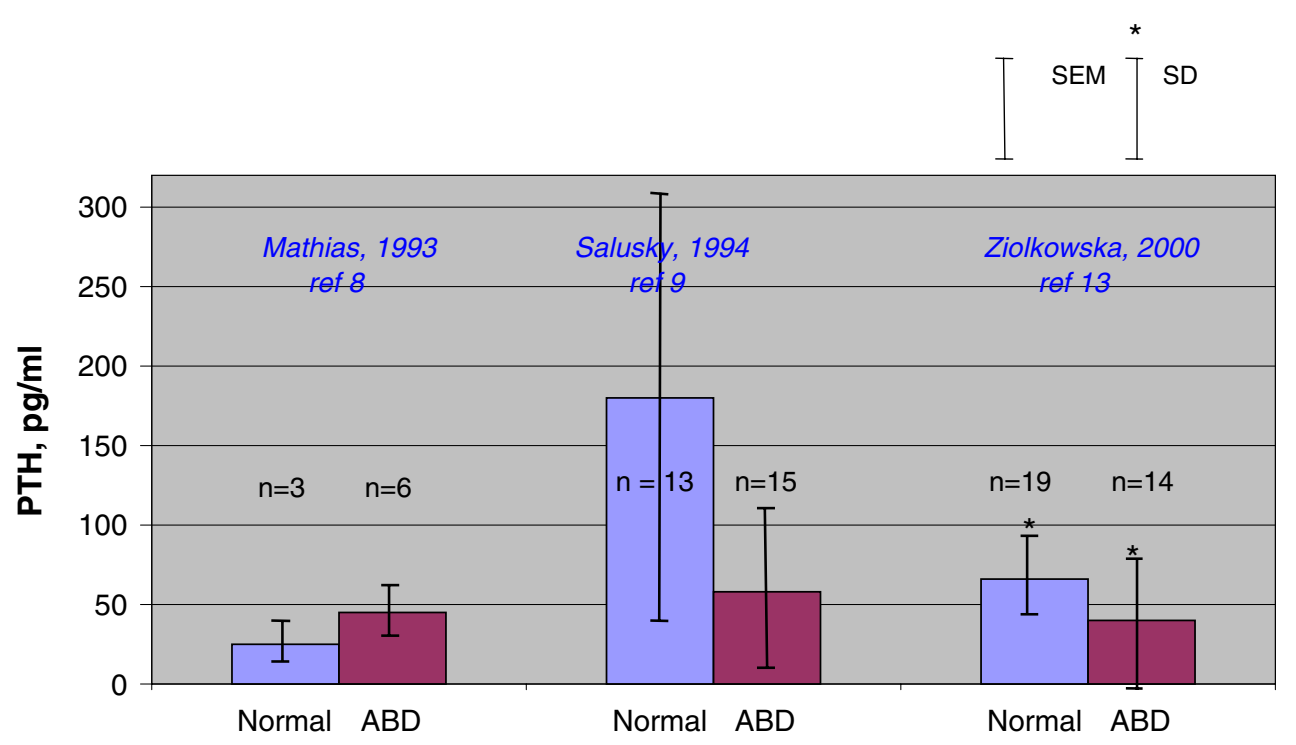

affected in the four patients who developed ABD, possibly because of the inhibiting effects of large, intermittent, doses of calcitriol on chondrocyte activity within the growth plate cartilage. In our 11 patients (Table 1) the rate of growth did not vary with the type of bone histology. Change in HtSDS over the previous $1.0(0.5-1.6)$ years was $+0.06(-0.11$ to $+0.15)$ in patients with $\mathrm{ABD},-0.29(-0.07$ to -0.50$)$ in those with mixed lesions, and $0.02(-0.34$ to +0.34$)$ in patients with high-turnover disease. However, numbers are small, and only much larger studies would be able to clarify the relationship between growth and bone histology.

Overall, reports of growth in children on dialysis are variable, with the majority showing a decline in HtSDS. It is difficult to dissect out the effects of renal bone disease from malnutrition, anaemia, inadequate dialysis and other causes of poor growth. On the other hand, we have found, in a review of the growth of 35 prepubertal children on dialysis for more than 1 year in our unit, that, even with PTH levels only slightly above normal, it is possible to prevent decline in HtSDS, and significant catch-up growth can occur in children less than 2 years $[16,17]$.

\section{PTH levels and vascular disease}

Adynamic bone disease due to aging, parathyroidectomy, aluminium and high doses of calcium-containing phosphate binders is associated with vascular calcification in adults [18]. Is there any evidence to associate PTH levels and vascular disease and calcification in children? This is a difficult question to answer, because of the inextricable relationships between phosphate, which is possibly the most potent vascular toxin, vitamin D, and PTH. Soft tissue calcification in paediatric patients is not a new phenomenon. The presence of coronary artery abnormalities at post- mortem in children who had been on HD was reported as long ago as 1976 [19], and autopsies of 120 children with uraemia, on dialysis, or following renal transplantation from 1960 to 1983 revealed soft tissue calcification in $60 \%$ [20]. More recently, histological evidence of intimal thickening and atherosclerotic plaques was found in five of 12 children with a mean (range) age of 14.6 (11-17) years on HD who were undergoing transplantation and was associated with calcification in the iliac artery of two [21].

Most studies of the effect of childhood end-stage renal failure (ESRF) on vascular outcomes are of young adults. As well as survival data, surrogate markers of structural and functional disease and calcification, such as carotid intima media thickness (CIMT) and distensibility, and pulse wave velocity (PWV), electron beam computed tomography (EBCT) and multi-slice CT scanning have been used to assess the development of vascular abnormality. Inevitably, because a significant number of patients in these follow-up cohorts have died from cardiovascular disease, the true incidence and severity of vascular abnormalities is likely to be greater than reports using surrogate markers would suggest. Duration of ESRF management and, in particular, dialysis, has been linked to worse outcomes in all studies.

Not all studies have addressed the effect of abnormalities of mineral metabolism on vascular anomalies; arterial stiffness was shown to be increased in the Dutch long-term follow-up study, but data on mineral metabolism were not available [22]. In a study from Germany, coronary artery calcification (CAC) was reported in $38 \%$ of 16 patients aged 14-39 years, but correlations with PTH were not made [23]. Three studies have concentrated on this aspect in young adults. In a second German study, CAC was found in $92 \%$ of 39 patients aged $19-39$ years on dialysis or after transplantation, and CIMT was increased. Calcification 
scores and CIMT correlated with the calcium $\times$ phosphate product and with $\mathrm{PTH}$, particularly if the level of C-reactive protein (CRP) was raised [24]. A further study from Salusky's group identified CAC in $88 \%$ of 16 patients aged over 20 years on dialysis, but in none of 23 patients aged less than this. The plasma calcium, calcium $\mathrm{x}$ phosphate product and intake of calcium, but not PTH levels, were greater in those with calcification [25]. The most recent paper included 40 patients aged $23.6 \pm 5.5$ years, of whom nine were on dialysis and 31 had received transplants. CIMT was not increased, but left ventricular hypertrophy was present in $62.5 \%$, and four $(10 \%)$ had CAC. Again, calcium intake from phosphate binders and vitamin D correlated with these abnormalities, and PTH was an independent predictor of left ventricle (LV) mass index [26].

There are five studies that address the problem principally in children, although in four of these studies patients in their twenties are included, i.e. patients who no longer have the dimension of growth affecting mineral balance. Increased plasma phosphate, calcium phosphate product, phosphate binder and calcitriol doses, and PTH predicted abnormal vascular structure and function, and PTH also correlated with left ventricle mass (LVM) index and poor diastolic function, in 16 patients on dialysis [27]. CIMT was increased in 37 patients on dialysis and in 34 after transplantation, particularly in the dialysis patients, and CIMT correlated with calcium $\times$ phosphate product, calcium-based phosphate binder and vitamin D intake, but not with PTH [28]. Spiral CT scanning in 53 patients (39 on dialysis, 14 after transplantation) detected CAC in $15 \%$. Mineral metabolism was a significant association, including higher time integrated phosphate, calcium $\times$ phosphate product and PTH, and calcium-containing phosphate binders and vitamin D intake [29]. A recent paper from the USA of 11 patients (four on HD, seven after transplantation) reported that seven had CAC. This included all the patients on dialysis. The only significant influencing factor was the dose of calcitriol. PTH levels were very high in all patients [30]. We have studied CIMT, PWV and CAC in 85 children of a younger age range (5 years to 18 years) who had undergone dialysis for at least 6 months. CIMT and calcification correlated with PTH levels. There was no difference from controls in CIMT and PWV in patients with PTH levels $<2 \times$ the upper limit of normal (44 children), but those with PTH levels $>2 \times$ the upper limit of normal (ULN) (41 children) had thicker CIMT, stiffer vessels and increased calcification. The dose of vitamin D strongly influenced all vascular measures [31]. Further investigation of 61 children on dialysis identified a bimodal effect of plasma levels of 1,25 (OH)2D3, such that levels both above and below the normal range were associated with increased CIMT and vascular calcification [32]. In summary, PTH was correlated with surrogate markers of vascular calcifi- cation in three out of the five paediatric studies [27, 29, 31] and two out of the three studies of young adults that have looked at this relationship [24, 26].

\section{Conclusions}

The evidence for optimum levels for PTH management in children with CKD is weak. This means that our current recommendations for manipulation of plasma calcium and phosphate, which are based upon controlling PTH within a specified range, may be flawed as a result, particularly in the light of emerging data suggesting a protective effect of at least small doses of vitamin D in cardiovascular health [33]. So what should our approach be? We want to provide our patients with the best outcome for bone health, growth and cardiovascular disease. We do know that hyperphosphataemia and a high calcium $\times$ phosphate product are toxic to the vasculature and should be prevented. We know that both too much and too little intake of calcium is bad. We know that high PTH levels and plasma levels of vitamin D that are either too low or too high are associated with increased cardiovascular morbidity. Clearly, therefore, we need to keep plasma phosphate, calcium and vitamin D levels in the normal range. Is there enough evidence in children to manipulate PTH levels to such abnormally high values as currently recommended by KDOQI and the European guidelines? Can intervention early in the course of CKD prevent the escape of the parathyroid gland from normal control mechanisms? Currently, until more research becomes available, recommendations can only be opinion based, and, therefore, consensus may be difficult. However, as growth rate can be maintained, and surrogate markers of cardiovascular disease are at their best in dialysed children with PTH levels of $<2 \times$ ULN, I would like to recommend that this should be the upper limit of the range that we should aim for in children with CKD stage 5.

\section{References}

1. Groothoff JW, Cransberg K, Offringa M, van de Kar NJ, Lilien MR, Davin JC, Heymans HS (2004) Long-term follow-up of renal transplantation in children: a Dutch cohort study. Transplantation 78:453-460

2. Moe S, Drüeke T, Cunningham J, Goodman W, Martin K, Olgaard K, Ott S, Sprague S, Lameire N, Eknoyan G (2006) Kidney disease: improving global outcomes (KDIGO). Definition, evaluation, and classification of renal osteodystrophy: a position statement from Kidney Disease: Improving Global Outcomes (KDIGO). Kidney Int 69:1945-1953

3. Rees L, Webb N, Brogan P (2007) Renal osteodystrophy In: Paediatric nephrology. Chapter 24. Oxford University Press, pp 420-428

4. Rostand SG, Drueke TB (1999) Parathyroid hormone, vitamin D, and cardiovascular disease in chronic renal failure. Kidney Int $56: 383-392$ 
5. http://www.kidney.org/professionals/kdoqi/guidelines_pedbone/ index.htm

6. Klaus G, Watson A, Edefonti A, Fischbach M, Rönnholm K, Schaefer F, Simkova E, Stefanidis CJ, Strazdins V, Vande Walle J, Schröder C, Zurowska A, Ekim M, European Paediatric Dialysis Working Group (EPDWG) (2006) Prevention and treatment of renal osteodystrophy in children on chronic renal failure: European guidelines. Pediatr Nephrol 21:151-159

7. Waller S, Reynolds A, Ridout D, Cantor T, Gao P, Rees L (2003) Parathyroid hormone and its fragments in children with chronic renal failure. Pediatr Nephrol 18:1242-1248

8. Mathias R, Salusky I, Harman W, Paredes A, Emans J, Segre G, Goodman W (1993) Renal bone disease in pediatric and young adult patients on hemodialysis in a children's hospital. J Am Soc Nephrol 12:1938-1946

9. Salusky IB, Ramirez JA, Oppenheim W, Gales B, Segre GV, Goodman WG (1994) Biochemical markers of renal osteodystrophy in pediatric patients undergoing CAPD/CCPD. Kidney Int 45:253-258

10. Goodman WG, Ramirez JA, Belin TR, Chon Y, Gales B, Segre GV, Salusky IB (1994) Development of adynamic bone in patients with secondary hyperparathyroidism after intermittent calcitriol therapy. Kidney Int 46:1160-1166

11. Hodson EM, Evans RA, Dunstan CR, Hills EE, Shaw PF (1982) Quantitative bone histology in children with chronic renal failure. Kidney Int 21:833-839

12. Watson AR, Kooh SW, Tam CS, Reilly BJ, Balfe JW, Vieth R (1988-1989) Renal osteodystrophy in children on CAPD: a prospective trial of 1-alpha-hydroxycholecalciferol therapy. Child Nephrology Urol 9:220-227

13. Ziólkowska H, Pańiczyk-Tomaszewska M, Debiński A, Polowiec Z, Sawicki A, Sieniawska M (2000) Bone biopsy results and serum bone turnover parameters in uremic children. Acta Paediatr 89:666-671

14. Yalçinkaya F, Ince E, Tümer N, Ensari A, Ozkaya N (2000) Spectrum of renal osteodystrophy in children on continuous ambulatory peritoneal dialysis. Pediatr Int 42:53-57

15. Kuizon BD, Goodman WG, Jüppner H, Boechat I, Nelson P, Gales B, Salusky IB (1998) Diminished linear growth during intermittent calcitriol therapy in children undergoing CCPD. Kidney Int 53:205-211

16. Cansick J, Waller S, Ridout D, Rees L (2007) Growth in prepubertal children on long-term dialysis. Pediatr Nephrol 22:1349-1354

17. Kari JA, Gonzalez C, Ledermann SE, Shaw V, Rees L (2000) Outcome and growth of infants with chronic renal failure. Kidney Int 57:1681-1687

18. London GM, Marty C, Marchais SJ, Guerin AP, Metivier F, de Vernejoul MC (2004) Arterial calcifications and bone histomorphometry in end-stage renal disease. J Am Soc Nephrology 15:1943-1951

19. Pennisi AJ, Heuser ET, Mickey MR, Lipsey A, Malekzadeh MH, Fine RN (1976) Hyperlipidemia in pediatric hemodialysis and renal transplant patients. Associated with coronary artery disease. Am J Dis Child 130:957-961
20. Milliner DS, Zinsmeister AR, Lieberman E, Landing B (1990) Soft tissue calcification in pediatric patients with end-stage renal disease. Kidney Int. 38:931-936

21. Nayir A, Bilge I, Kiliçaslan I, Ander H, Emre S, Sirin A (2001) Arterial changes in paediatric haemodialysis patients undergoing renal transplantation. Nephrol Dial Transplant 16:2041-2047

22. Groothoff JW, Gruppen MP, Offringa M, de Groot E, Stok W, Bos WJ, Davin JC, Lilien MR, Van de Kar NC, Wolff ED, Heymans HS (2002) Increased arterial stiffness in young adults with end-stage renal disease since childhood. J Am Soc Nephrol 13:2953-2961

23. Eifinger F, Wahn F, Querfeld U, Pollok M, Gevargez A, Kriener P, Gronemeyer D (2000) Coronary artery calcifications in children and young adults treated with renal replacement therapy. Nephrol Dial Transplant 15:1892-1894

24. Oh J, Wunsch R, Turzer M, Bahner M, Raggi P, Querfeld U, Mehls O, Schaefer F (2002) Advanced coronary and carotid arteriopathy in young adults with childhood-onset chronic renal failure. Circulation 106:100-105

25. Goodman WG, Goldin J, Kuizon BD, Yoon C, Gales B, Sider D, Wang Y, Chung J, Emerick A, Greaser L, Elashoff RM, Salusky IB (2000) Coronary-artery calcification in young adults with end-stage renal disease who are undergoing dialysis. N Engl J Med 18:1478-1483

26. Briese S, Wiesner S, Will JC, Lembcke A, Opgen-Rhein B, Nissel R, Wernecke KD, Andreae J, Haffner D, Querfeld U (2006) Arterial and cardiac disease in young adults with childhood-onset end-stage renal disease-impact of calcium and vitamin D therapy. Nephrol Dial Transplant 21:1906-1914

27. Mitsnefes MM, Kimball TR, Kartal J, Witt SA, Glascock BJ, Khoury PR, Daniels SR (2005) Cardiac and vascular adaptation in pediatric patients with chronic kidney disease: role of calciumphosphorus metabolism. J Am Soc Nephrol 16:2796-2803

28. Litwin M, Wühl E, Jourdan C, Trelewicz J, Niemirska A, Fahr K, Jobs K, Grenda R, Wawer ZT, Rajszys P, Tröger J, Mehls O, Schaefer F (2005) Altered morphologic properties of large arteries in children with chronic renal failure and after renal transplantation. J Am Soc Nephrol 16:1494-1500

29. Civilibal M, Caliskan S, Adaletli I, Oflaz H, Sever L, Candan C, Canpolat N, Kasapcopur O, Kuruoglu S, Arisoy N (2006) Coronary artery calcifications in children with end-stage renal disease. Pediatr Nephrol 21:1426-1433

30. Lumpaopong A, Mathew AV, John E, Jelnin V, Benedetti E, Testa G, Oberholzer J, Sankary H, Ruiz C (2007) Early coronary calcification in children and young adults with end-stage renal disease. Transplant Proc 39:37-39

31. Shroff RC, Donald AE, Hiorns MP, Watson A, Feather S, Milford D, Ellins EA, Storry C, Ridout D, Deanfield J, Rees L (2007) Mineral metabolism and vascular damage in children on dialysis. J Am Soc Nephrol 18:2996-3003

32. Shroff R, Egerton M, Bridel M, Shah V, Donald AE, Cole TJ, Hiorns MP, Deanfield JE, Rees L (2007) The impact of vitamin D levels on vascular structure and calcification in children on dialysis. J Am Soc Nephrol, in press

33. Langman CB, Brooks ER (2006) Renal osteodystrophy in children: a systemic disease associated with cardiovascular manifestations. Growth Horm IGF Res 16 [Suppl A]:S79-S83 